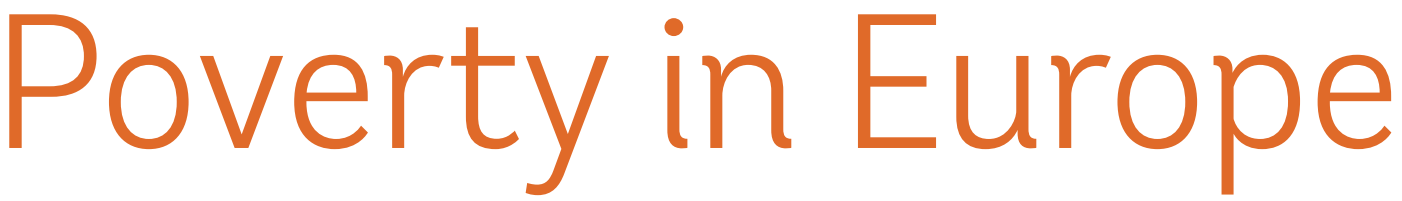

March 2016

Poverty and Equity Global

Practice

\title{
Knowledge Externalities from Poverty Mapping in the European Union
}

The Poverty Mapping in the European Union (EU) project, an initiative of the World Bank and European Commission (EC) in cooperation with EU member states, has developed a set of high-resolution poverty maps by using information from recent national population censuses and household income surveys to estimate the rates of monetary poverty for small geographic areas in EU member states. This disaggregated information can help guide allocations of EU funds to the areas in highest need as well as inform decision making and policies at the national and sub

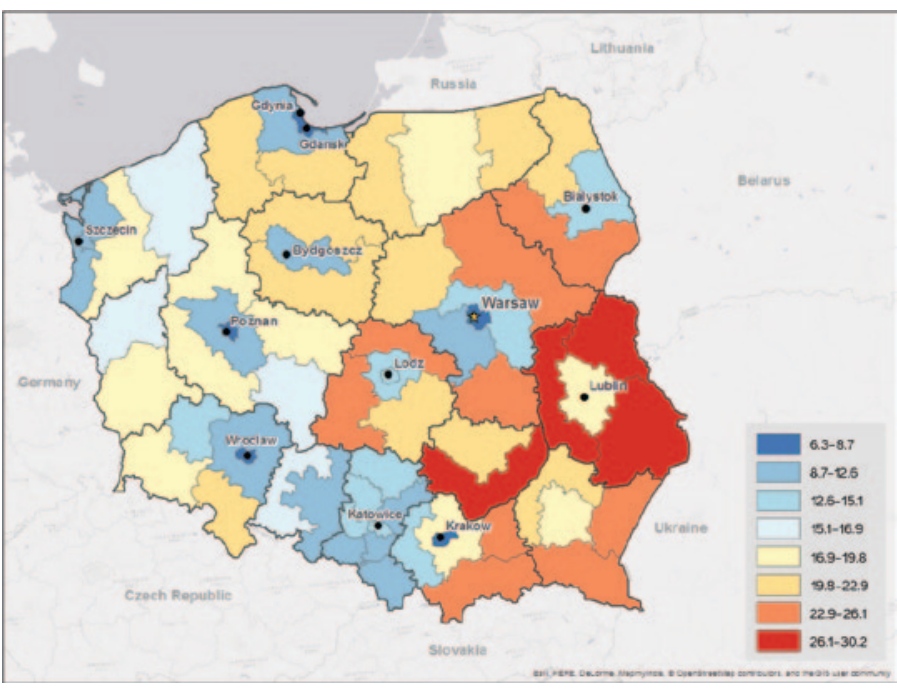

Source: Estimates using data from the 2011 EU-SILC and the 2011 Census of Population and Housing collected by the Central Statistical Office of Poland. -national levels in each of the

EU member states. This brief outlines several of the key knowledge externalities gained in the context of this project that have improved the World Bank's approach to poverty mapping, including methodological innovations in small area poverty estimation and enhancements to the publicly available poverty mapping software PovMap.

\section{Background}

According to the latest data from Eurostat, more than 122 million people in the EU-nearly 25 percent of EU citizens - are at risk of poverty or social exclusion. ${ }^{1}$ One of the five head-

\footnotetext{
${ }_{1}$ Eurostat Data Explorer. http://ec.europa.eu/eurostat /web/income-and-living-conditions/data/main-tables. Accessed January 15, 2016.
}

line targets of the Europe 2020 strategy is to reduce the number of people living at risk of poverty or social exclusion by 20 million by the year 2020. In its 2014-2020 multiannual financial framework the EU has budgeted one trillion euros to support growth and jobs, which will contribute to reducing poverty and social exclusion. Success depends on developing the right policies and programs and targeting them effectively. Just as rates of poverty and social exclusion vary widely across EU member states, there is also a high degree of variability in living standards within EU member states. It follows that promoting convergence of living standards across the EU requires detailed knowledge of the disparities in living standards within 
each member state, and especially in those member states with high levels of poverty and social exclusion.

From 2011 to 2014, the EC and the World Bank, in cooperation with individual EU member states, have produced a set of high-resolution poverty maps. The objective is to help the EC and EU member states target funds and programs in the 2014-2020 budget cycle most efficiently to the areas in highest need. These high-resolution poverty maps combine information from recent national population censuses and EU Statistics on Income and Living Conditions (EU-SILC) household surveys ${ }^{2}$ to estimate the rates of monetary poverty for small geographic areas such as counties, districts, or municipalities. In previous years, the EC has had to rely on less detailed data and maps at the "NUTS 2 " level (for example, the eight development regions in Romania) for program planning and the allocation of EU funds. ${ }^{3}$ The greater geographic disaggregation of the new poverty maps reveals which parts of these larger regions have particularly high rates of poverty risk and require greater attention for poverty reduction programs. When combined with data on population size per small area, they also provide information on where most of the poor are located. The poverty maps not only help guide allocations of EU funds, but may also be used for decision making and policies at the national and sub-national levels in each of the EU member states.

In the context of developing this work, several key knowledge externalities were generated that have influenced the World Bank's approach to poverty mapping, including methodological innovations in small area poverty estimation. These innovations have been incorporated in the PovMap software package developed by the World Bank that is freely available and in wide use across the world. Thus, in addition to meeting the direct objectives of the World Bank Group (WBG)/ EC poverty mapping initiative in the EU, the project has had important spillover benefits

\footnotetext{
2 For most countries the 2011 population census was used along with EU-SILC from 2011 or 2012.

3 The NUTS (Nomenclature des Unités Territoriales Statistiques) classification is a hierarchical system for sub-dividing the economic territory of the European Union for the development of regional statistics, regional socioeconomic analysis, and the framing of EU regional policies. To date the NUTS 2 classification has been used for determining eligibility for aid from European Structural Funds. Below the NUTS 3 classification areas are defined according to Local Administrative Units (LAU). Most EU member states have LAU 1 and LAU 2 divisions, but some only have LAU 2 .
}

that may enhance the quality of small area poverty estimation in low- and middleincome countries as well.

Poverty Mapping Approaches: ELL vs EB Since the late 1990s, the WBG has played a pioneering role in the small area estimation of poverty using microdata, led by cutting-edge research within the Development Economics Research Group. The main approach used by the WBG and its partners for approximately the past 15 years is the Elbers-LanjouwLanjouw (ELL) (Elbers, Lanjouw, and Lanjouw 2003) method, which has been empirically applied now in over 60 countries. ELL uses a massive out-of-sample prediction to impute welfare (usually income or consumption) data for households recorded in a national population census. The imputation process uses common explanatory variables such as individual, household, and community characteristics that are available in both the household survey and the census to predict the welfare values in the census. These imputed welfare values for census households can then be aggregated to estimate poverty and inequality statistics for small areas, with sufficient statistical precision to permit reliable ranking of small areas by poverty incidence.

Molina and Rao (2010) proposed an enhancement to the ELL approach using an Empirical Bayes (EB) prediction method. EB expands upon conventional ELL methods by using the survey data to inform the estimation of random area effects. However, as Elbers and van der Weide (2014) note, there are methodological trade-offs to each approach. Whereas conventional ELL methods accept "a certain loss in efficiency by not fully utilizing all available information," EB enhanced ELL methods "accept a loss in precision that might stem from a misspecification of the error distribution functions." Which estimation method would be preferable for a given country, however, ultimately depends on the nature of its dataset. Elbers and van der Weide suggest that the choice between EB and ELL methods is largely determined by two key factors: (a) how much information one stands to ignore/lose, which in turn depends on how many of the small areas have been sampled by the income survey and the size of the area error relative to the total error, and (b) the degree of non-normality found in the data.

\section{New Insights from the EU Member States \\ In the preliminary stages of the poverty mapping project for the EU, a methodological}


validation study was conducted to compare these different approaches for small area poverty estimation with the intent to critically evaluate the methods used within the WBG as well as their applicability to a European setting, where sample designs are quite different from those found in lowincome countries. The exercise benefited not only from the knowledge of technical experts in academia and European National Statistical Institutes (NSIs), but also from users of this type of information in the EC.

The pilot study tested the empirical applications of ELL and EB using unique income registry datasets in Denmark and Slovenia to validate different approaches. By testing selected variations of ELL and EB on data for which income data were available for the entire population, it was possible to see which approaches came closer to the "true" poverty rates as measured directly by the income registry data. These findings were then used to inform the WBG-led poverty mapping exercises in Estonia, Hungary, Latvia, Poland, Romania, the Slovak Republic, and Slovenia. The findings also provided the basis for poverty mapping in 17 other EU Member States carried out by a Nordic research consortium under a separate contract with the EC.

In regard to the first decisive factor for choosing a model for small area poverty estimation, how much data information one stands to ignore/lose, two key observations emerged from the poverty mapping exercises. The first observation recognizes that the number of small areas covered by the EU-SILC-the survey used by EU member states to collect household data on incometends to be substantial. It is typical for the EU-SILC to cover 50-100 percent of the small areas for which poverty is to be estimated, compared to a norm of 5-25 percent in low income countries. This would suggest that EB estimation may be preferable in the European context. However, the second observation reveals that the size of the location effect is relatively small in the EU member states. This would suggest that the gains from EB are expected to be modest for most areas-although there may still be a handful of areas where EB could realize a substantial improvement.

This brings us to the second decisive factor for choosing a small area estimation method, the degree of non-normality present in the data. If the degree of non-normality in the data is notable, then ELL would be the preferred method. However, the amount of empirical evidence collected on the question of normality is rather limited. Monte Carlo simulations carried out under this project show that ignoring the non-normality of errors can lead to biased estimates of poverty and inequality, as high as 2-3 percent on a poverty rate of 20-30 percent (Elbers and Van der Weide 2014). Thus, given the lack of information on normality, Elbers and Van der Weide developed an alternative methodological approach in context of the EU Poverty Mapping project, which would accommodate both EB and non-normality: the Normal Mixtures-Empirical Bayes (NM-EB) method.

Finally, through this process of methodological validation, it became apparent that the current approaches for small area estimation have difficulties estimating poverty accurately in the "tails" of the distribution, or those areas with very high or very low poverty rates. This will be an important avenue of further research in order to continue improving the way that poverty mapping is practiced both within the World Bank and elsewhere.

Introducing PovMap 2.5

In 2004, the World Bank's Development Economics Research Group developed special-purpose software, known as PovMap, for the estimation of poverty in small areas. The main advantage of using PovMap instead of standard statistical software is its speed and efficiency in performing hundreds of simulations on large census data sets containing millions of observations and its handling of complex error structures. Its graphical user interface also simplifies operations for the user, while retaining the required rigor and complexity of the computations as background operations. From 2004 until 2013, PovMap relied on conventional ELL approaches, making this methodology readily available to a wider audience of users.

From the outset, the WBG/EU poverty mapping project supported new development and enhancements to PovMap software. In response to the methodological findings from poverty mapping in the EU (Van der Weide 2014), several new features were added to the latest release of the software, PovMap 2.5. This new version offers increased flexibility for users to choose between conventional ELL methods or EB enhanced methods. An additional option to use NM-EB methods is being developed and tested and will be added in a subsequent release of PovMap. As PovMap is widely used by analysts both inside and outside the WBG to produce poverty maps in low- and 


\section{Conclusion}

The knowledge externalities from the Poverty of small area poverty estimation methods, ings have since further developed the poverty in this field. The initiative has helped build 2012 and 2013 Conferences on Small Area tion in countries around the world. As this

\section{Related Publications}

The following publications and academic

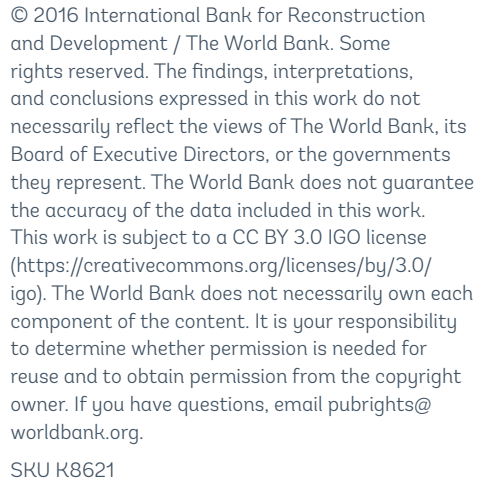

middle-income countries, these methodological innovations are expected to have a wide impact. Mapping in the EU project have notably changed the way the WBG approaches poverty mapping. The project offered a rare opportunity for the systematic validation which succeeded in quantifying the impact of adding EB to the ELL approach. These findmapping research agenda within the World Bank and fostered innovation more broadly bridges between researchers in statistics and econometrics, promoting interaction and exchange of ideas through featured sessions at the 2012 Joint Statistical Meetings and the Statistics. Through academic conferences, engagement with partners in NSls, and enhancements to the PovMap software these findings are gaining prominence, encouraging greater collaboration across methodological camps, and ultimately improving the technical capacity for small area poverty estimatype of technical engagement in middle and high income countries can provide a platform for sophisticated innovation, it has important implications for low income countries as well. With the development of improved tools and training, these technical advancements can be adapted and used in settings with weaker data and analytical capacity. papers were produced in the context of the Poverty Mapping in the EU task:

Working Paper 6962. World Bank Group, Washington, DC.

Van der Weide, Roy. 2014. "GLS Estimation and Empirical Bayes Prediction for Linear Mixed Models with Heteroskedasticity and Sampling Weights: A Background Study for the POVMAP Project." World Bank Policy Research Working Paper 7028. World Bank Group, Washington, DC.

\section{About the Team}

\section{World Bank Staff and Consultants}

Kenneth Simler (Task Team Leader),

Robin Audy, Alexandru Cojocaru, Céline Ferré, Indiana Fonseca, Azhar Hussain, Maureen Itepu, Sandor Karacsony, Joost de Laat, Peter Lanjouw, Katarina Mathernova, Lei Pan, Ericka Rascon, Thomas Sohnesen, Roy van der Weide, Qinghua Zhao

\section{National Statistical Institutes \\ Estonia: Julia Aru, Kaja Sõstra \\ Hungary: Judit Dobszayné Hennel,}

Éva Ménesi, Ildikó Merkl

Latvia: Viktors Veretjanovs

Poland: Maciej Beresewicz,

Tomasz Józefowski, Tomasz Klimanek, Jacek Kowalewski, Anna Małasiewicz, Andrzej Młodak, Marcin Szymkowiak, Łukasz Wawrowski

Romania: Andreea Cambir, Nicoleta Caregea, Silvia Pisica

The Slovak Republic: Viera Doktoríková, Róbert Vlačuha

Slovenia: Danilo Dolenc, Tomaž Smrekar

\section{References}

Elbers, C., Lanjouw, J. and Lanjouw, P. 2003. "Micro-Level Estimation of Poverty and Inequality." Econometrica 71: 355-64

Elbers, C., van der Weide, R. 2014. "Estimation of Normal Mixtures in a Nested Error Model with an Application to Small Area Estimation of Poverty and Inequality." World Bank Policy Research Working Paper WPS 6962. Washington, DC: World Bank Group.

Elbers, Chris and Roy van der Weide. 2014.

"Estimation of Normal Mixtures in a Nested Error Model with an Application to Small Area Estimation of Poverty and Inequality." World Bank Policy Research
Molina, I. and Rao, J. 2010. "Small Area Estimation of Poverty Indicators." Canadian Journal of Statistics 38: 369-85.

Van der Weide, Roy. 2014. A Review of Empirical Bayes Prediction Using Sampling Weights with Poverty Mapping in Mind. World Bank Group. 